\title{
SORAFENIB INDUCED ACNEIFORM ERUPTIONS: A CASE REPORT
}

\author{
BALAJI O, AMITA D, NAVIN PATIL*
}

Department of Pharmacology, Kasturba Medical College, Manipal, Karnataka, India. Email: navin903@gmail.com

Received: 27 December 2016, Revised and Accepted: 14 January 2017

\begin{abstract}
Sorafenib an oral tyrosine kinase inhibitor is used in the treatment of hepatocellular carcinoma, renal cell carcinoma, and thyroid cancer. Sorafenib acts by inhibiting various kinases such as tyrosine kinase, rearranged during transfection tyrosine kinase, endothelial growth factor receptor, vascular endothelial growth factor 2 and 3 inhibits angiogenesis, and cell proliferation. Acneiform eruptions are known side effect of epidermal growth factor receptor inhibitors but acneiform eruptions with sorafenib is seldom seen. Hence we report a case of sorafenib - induced acneiform eruptions.
\end{abstract}

Keywords: Sorafenib, Epidermal growth factor receptor, Acneiform eruptions, Adverse drug reactions.

(C) 2017 The Authors. Published by Innovare Academic Sciences Pvt Ltd. This is an open access article under the CC BY license (http://creativecommons. org/licenses/by/4. 0/) DOI: http://dx.doi.org/10.22159/ajpcr.2017.v10i4.16805

\section{INTRODUCTION}

Sorafenib an oral tyrosine kinase inhibitor is used in the treatment of hepatocellular carcinoma, renal cell carcinoma, and thyroid cancer. Cutaneous adverse reactions are common with sorafenib but acneiform eruptions are very rare, although it has a widely-reported association with epidermal growth factor receptor (EGFR) inhibition and EGFR inhibitors with incidence between $20 \%$ to $90 \%[1,2]$.

\section{CASE REPORT}

Informed consent was taken from the patient for this case report. A 21-year-old male, known case of cirrhosis of liver, hepatocellular carcinoma who had underwent left lobe of liver resection was admitted with complaints of abdominal pain. On examination, vitals were stable, systemic examination was normal and laboratory investigations were normal. Ultrasound abdomen revealed altered echotexture in right lobe of liver with thrombosis in main pancreatic duct causing partial obstruction. The patient was conservatively managed with antibiotics and fluids. He was also started on sorafenib $200 \mathrm{mg}$ twice daily, and after starting the medication by $3^{\text {rd }}$ day, he developed rashes all over his body and pimples on his back. On examination skin, colored papules were seen over chest, face, and scalp, and back. Scaling was also noted in scalp. A diagnosis of sorafenib induced acneiform eruptions was made. The patient was started with isotretinoin with clindamycin cream to be topically applied $1 \mathrm{hr}$ once in a day for 2 weeks. Furthermore, Salisia KT shampoo was given for scalp lesions for 2 weeks. Sorafenib was continued at the same dosage. Patient improved on discharge.

\section{DISCUSSION}

Sorafenib, a bi-aryl urea class of drug with a molecular weight of $630 \mathrm{ug} / \mathrm{mol}$ [3] acts by inhibiting various kinases such as tyrosine kinase, rearranged during transfection tyrosine kinase, EGFR, vascular endothelial growth factor 2 and 3 inhibits angiogenesis, and cell proliferation [1]. In contrast to EGFR inhibitors, cutaneous drug reactions are less with sorafenib. Some of the common cutaneous toxicities of sorafenib are listed in Table 1. Acneiform eruptions are known side effect of EGFR inhibitors with an incidence ranging between $20 \%$ and $90 \%$ [4], but acneiform eruptions with sorafenib is seldom seen with only 5 definite cases reported so far in literature with a median time of 4 weeks for development of lesions [5-7]. Usually, it is mistaken for acute generalized exanthematous pustulosis but that is more common with antiepileptic group of drugs [8]. Normal epidermal growth process depends on the presence of EGFR present in follicular and epidermal keratinocytes. Tyrosine kinase receptor is attached to the intracellular domain of EGFR. This is responsible for phosphorylation of downstream signaling proteins, and one of them is the Raf/MEK/ERK pathway which is involved in cell cycle progression and proliferation. Sorafenib inhibits tyrosine kinase thereby preventing phosphorylation and hence forth modifying the action of Raf/MEK/ ERK pathway. This is mainly responsible for skin reactions associated with sorafenib. Treatment depends mainly on severity of lesions. Since acneiform eruptions responds well to oral as well as local therapy, there is no dose limitation or need for stopping sorafenib. Preventive measures are not well developed, yet preventive treatment with oral fusidic acid or topical $4 \%$ erythromycin emulsion has been satisfactory in reducing the occurrence of pustules. Intranasal mupirocin is usually used to avoid secondary bacterial infections [7].

In our case patient developed acute acneiform eruptions within 4 days of starting treatment with sorafenib and other medications causing acne was ruled out. Causality assessment, severity, and preventability assessment were done as per Naranjo's, Hartwig's, and Thornton's scaling [9], respectively (Table 2). A probable causal relationship was established, and hence sorafenib was confirmed to be the culprit.

\section{CONCLUSION}

Sorafenib now being a potential new drug in the treatment of solid tumors and skin related toxicities like acneiform eruptions being

Table 1: Cutaneous adverse reactions associated with sorafenib

\section{Alopecia}

Hand-foot skin reaction

Erythematous eruption on trunk

"Rash"/desquamation

Seborrheic dermatitis-like facial erythema

Stomatitis

Subungual splinter hemorrhage

Xerosis

Cheilitis

Epidermal cyst on face

Erythema marginatum hemorrhagicum

Genital (labial and scrotal) eczema

Eruptive melanocytic nevi

Leukocytoclastic vasculitis

Nonpigmented fixed drug eruption

Perforating folliculitis

Spiny follicular hyperkeratosis eruption 
Table 2: Adverse drug reaction assessment

$\begin{array}{ll}\text { Naranjo's scale } & \text { Probable } \\ \text { Hartwig's scale } & \text { Mild severity } \\ \text { Thorntons's scale } & \text { Not preventable }\end{array}$

very rare when compared to EGRF inhibitors and in comparison, to other cutaneous reactions due to sorafenib. Hence, proper preventive measures can be advised to avoid extensive lesions with papules. Further prospective studies can be done to find out whether dose reduction or discontinuation of sorafenib has better outcomes in the management of acneiform eruptions.

\section{REFERENCES}

1. Lee WJ, Lee JL, Chang SE, Lee MW, Kang YK, Choi JH, et al. Cutaneous adverse effects in patients treated with the multitargeted kinase inhibitors sorafenib and sunitinib. $\mathrm{Br} \mathrm{J}$ Dermatol 2009;161(5):1045-51.

2. Scandurra G, Aiello RA, Alì M, Taibi E, Sanò MV, Todaro FM, et al.
Appropriate management of cutaneous adverse events maximizes compliance with sorafenib treatment: A single-center experience. Future Oncol 2012;8(5):609-15.

3. Ghatak SB, Panchal SJ. Sorafenib in hepatocellular carcinoma: Hype or hope. Int J Pharm Pharm Sci 2011;3 Suppl 4:1-4.

4. Pickert A, Hughes M, Wells M. Chloracne-like drug eruption associated with sorafenib. J Drugs Dermatol 2011;10(11):1331-4.

5. Cohen PR. Sorafenib-associated facial acneiform eruption. Dermatol Ther (Heidelb) 2015;5(1):77-86.

6. Joncas V, Sammour R, Krasny M, Bouffard D, Provost N. A distinctive cutaneous reaction to sorafenib and a multikinase inhibitor. Int $\mathrm{J}$ Dermatol 2008;47:767-9

7. Fleta-Asín B, Vañó-Galván S, Ledo-Rodríguez A, Truchuelo-Díez M, Jaén-Olasolo P. Facial acneiform rash associated with sorafenib. Dermatol Online J 2009;15(4):7.

8. Patil N, Kunder SK, Avinash A, Pathak A, Madhyastha S, Rao K, et al. Phenytoin-Induced acute generalized exanthematous pustulosis. Asian J Pharm Clin Res 2016;9(2):10-1

9. Patil N, Rao NK, Balaji O, Hande HM, Rao R, Varghese G, et al. Indapamide induced SIADH with hypokalaemia: A case report. Res J Pharm Biol Chem Sci 2016;7(3):2693. 